\title{
Innovative Laboratory Projects for a Measurements and Instrumentation Course
}

\section{Prof. David R. Loker, Penn State Erie, The Behrend College}

David R. Loker received the M.S.E.E. degree from Syracuse University in 1986. In 1984, he joined General Electric (GE) Company, AESD, as a design engineer. In 1988, he joined the faculty at Penn State Erie, The Behrend College. In 2007, he became the Chair of the Electrical and Computer Engineering Technology Program. His research interests include wireless sensor networks, data acquisition systems, and communications systems.

\section{Mr. Stephen A. Strom, Penn State Erie, The Behrend College}

Stephen Strom is a lecturer in the Electrical and Computer Engineering Technology department of Penn State Behrend, and holds a B.S. in electrical engineering from Carnegie Mellon University. His career includes over thirty years experience in designing and programming embedded systems and has multiple patents for both hardware designs and software algorithms 


\title{
Innovative Laboratory Projects for a Measurements and Instrumentation Course
}

\begin{abstract}
A typical Electrical and Computer Engineering Technology program includes a 3-credit upperdivision Measurements \& Instrumentation course with an embedded laboratory component. There are three main sections for the course: LabVIEW programming with data acquisition, sensors and signal conditioning, and design of measurement and control systems. Laboratory activities mirror the lecture materials and are designed to reinforce the students understanding of LabVIEW and its data analysis capabilities. Laboratory projects, each consisting of one to two weeks in length, are completed by a team of students, and each team contains no more than two students. Labs covered in this course include the design of a calculator, modeling temperature sensors, and design of signal conditioning circuits. Various measurement systems are also designed, including temperature measurement systems, weighing system using strain gages, distance measurement system using an ultrasonic ranging module, and machine vision system using a USB webcam. Additionally, students design a conveyor control system using a mock-up of a three-station conveyor, and an instrumentation control system for automatically determining the frequency response of a lowpass filter using a digital storage oscilloscope with a built-in waveform generator. Several labs require the design of state machines.
\end{abstract}

The intent for this paper is to provide a detailed summary of several of the above innovative laboratory projects for the course to illustrate measurement and control applications with LabVIEW as the software development environment. For each of the laboratory projects, this paper provides a summary of the contents of student reference materials, lab handouts, and engineering requirements. Project assessment results are provided, and recommendations are included to help ensure student success on each of the projects.

\section{Introduction to the Measurements and Instrumentation Course}

This is a required junior-level course for Electrical and Computer Engineering Technology students. The objectives of the course are for students to be able to ${ }^{1}$ :

- Use LabVIEW as a programming language.

- Mathematically model sensors using LabVIEW.

- Analyze and design signal conditioning circuits.

- Design and implementation of measurement and control systems.

This course is lab intensive and utilizes LabVIEW with a myDAQ device as a primary vehicle for the design of measurement systems ${ }^{2-4}$. The course is three credits with two hours of lecture and two hours of lab per week. The lecture content of the course is divided into three primary sections: Programming applications using LabVIEW (7 weeks), Data acquisition, sensors, and signal conditioning (3 weeks), and Design of measurement systems (5 weeks). 
The lab content of the course is designed to support the material discussed during lecture. Most of the labs are considered design projects since they include a series of engineering requirements.

Depending upon the scope of the lab, engineering requirements may include designing a hardware interface, designing a graphical user interface, designing the software architecture for the program, and implementing an operating sequence. Each lab is designed to be completed in one or two weeks by a student team that consists of no more than two students (some students prefer to work by themselves), where students pick their team members at the beginning of the semester. For many of the labs, students are expected to work outside of the scheduled lab time in order to complete the objectives. A listing of the projects for the course is shown below.

- Lab 1: Software-defined Calculator

- Lab 2: Type-K Thermocouple

- Lab 3: Type-K and Type-J Thermocouple

- Lab 4: Analog Input for Resistance Measurement

- Lab 5: Temperature Measurement System using a Thermistor

- Lab 6: Conveyor System with State Machine

- Lab 7: Digital Voltmeter

- Lab 8: Non-contact Distance Measurement

- Lab 9: Signal Conditioning Circuit for an RTD

- Lab 10: Measurement System for Applied Mass

- Lab 11: Machine Vision

- Lab 12: Instrument Control over USB Interface
(1 week)

(1 week)

(1 week)

(1 week)

(2 weeks)

(2 weeks)

(1 week)

(1 week)

(2 weeks)

(1 week)

(1 week)

(1 week)

The purpose of this paper is to provide a detailed summary of several innovative laboratory projects for the course to illustrate measurement and control applications using LabVIEW with the myDAQ as the development environment.

\section{Temperature Measurement System using a Thermistor}

The purpose of this lab project (Lab 5) is to use LabVIEW with the myDAQ and a thermistor (part number RL2006-13.3K-140-D1) to design a temperature measurement system. Datasheets for the thermistor were provided to the students. The engineering requirements for the project are listed below.

Special features:

- Program designed using LabVIEW

- Analog input of the myDAQ used for interfacing to the thermistor voltage divider circuit for measuring temperature

- Thermistor (part number RL2006-13.3K-140-D1) used as the temperature sensor

- Fluke $87 \mathrm{~V}$ DMM with the thermocouple probe used as the temperature standard

User Interface Requirements:

- One numeric indicator showing the temperature in ${ }^{\circ} \mathrm{C}$ Functional Requirements:

- Designed operating temperature range: $0^{\circ} \mathrm{C}$ to $100^{\circ} \mathrm{C}$

- Implement thermistor equation that converts $\mathrm{R}_{\mathrm{T}}$ to $\mathrm{T}$. 
- Temperature measurement range: $25^{\circ} \mathrm{C}$ to $75^{\circ} \mathrm{C}$ with accuracy within $+/-5^{\circ} \mathrm{C}$

An example of the screen capture of a student's LabVIEW front panel and block diagram are shown below in Figure 1. For this project, students needed to implement the equation characterizing the relationship between resistance and temperature for the thermistor. Figure 1(b) includes a MathScript Node that determines the resistance of the thermistor (based on the voltage divider configuration) and implements the mathematical equation of the thermistor for calculating temperature in Kelvin from thermistor resistance. Then, the temperature is converted to Celsius and Fahrenheit.

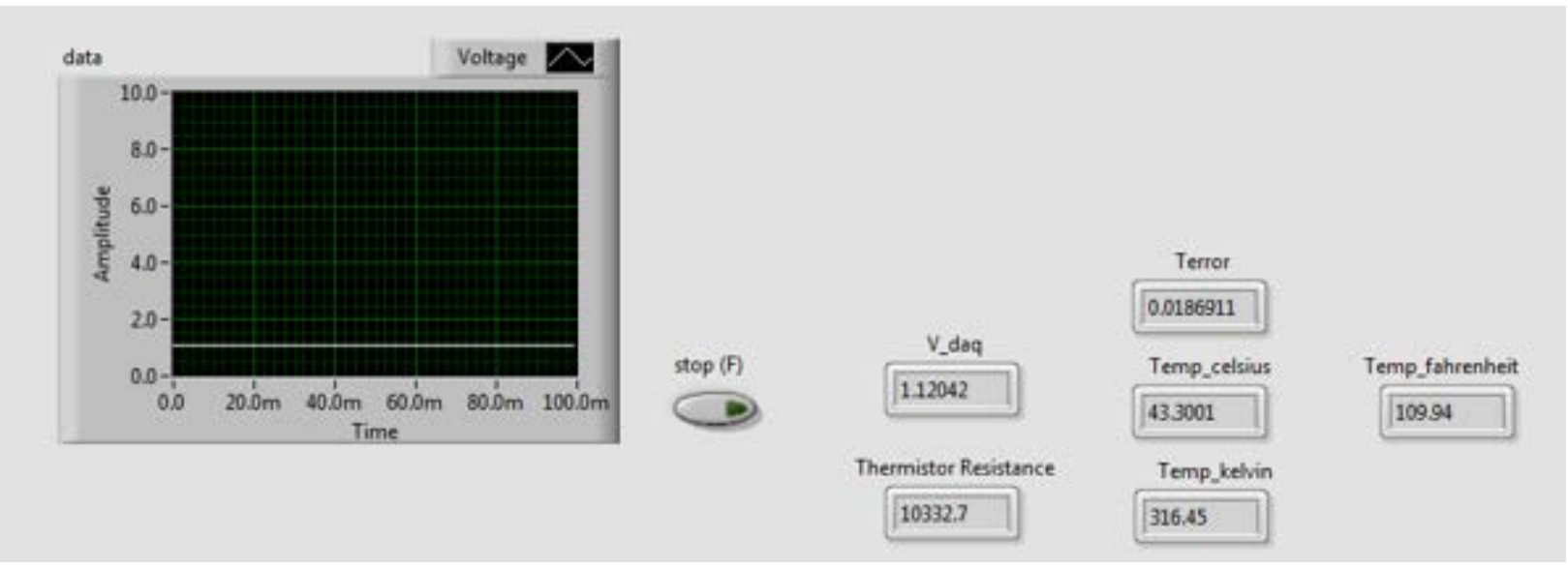

Figure 1(a). LabVIEW front panel of Temperature Measurement System using a Thermistor 


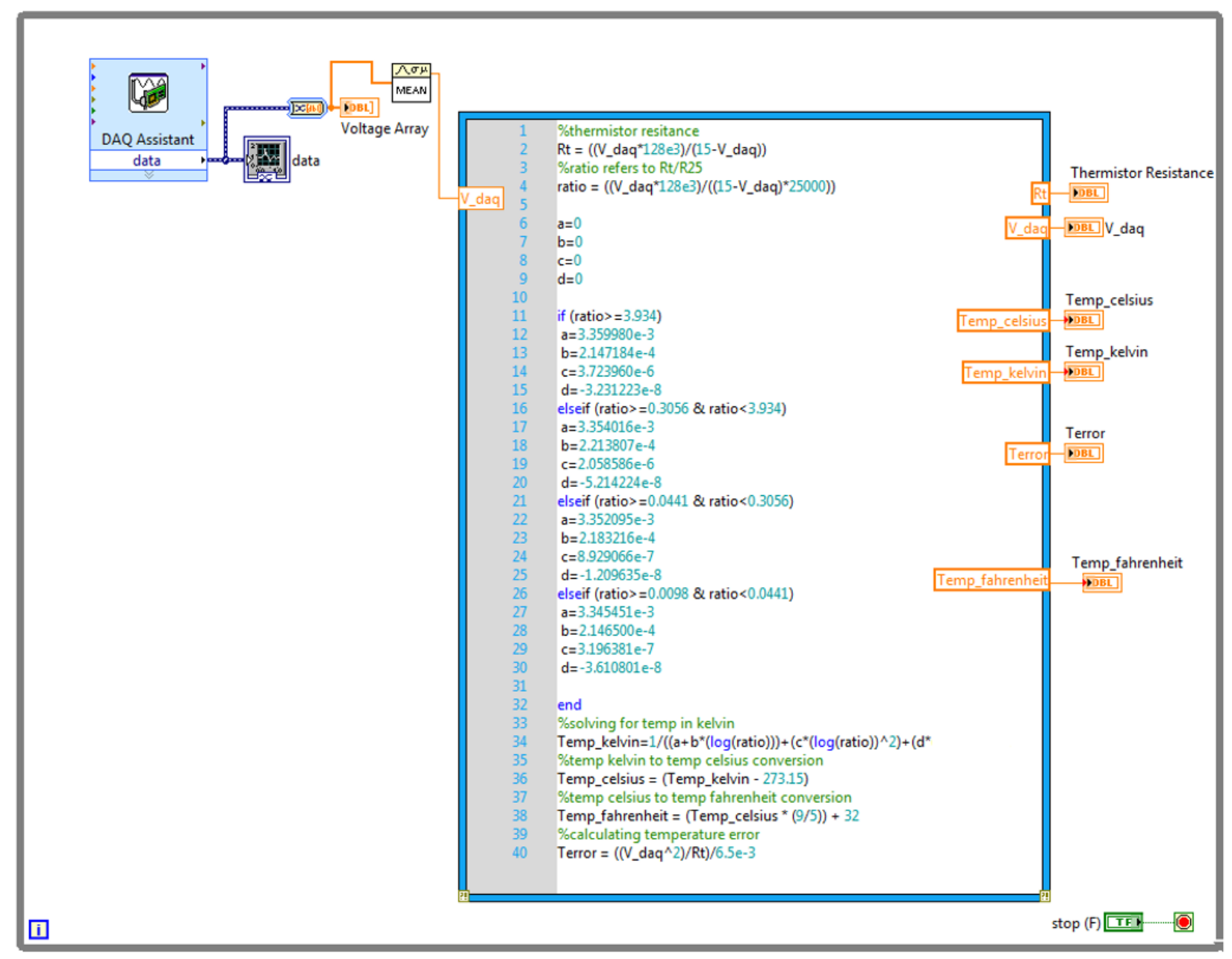

Figure 1(b). LabVIEW block diagram of Temperature Measurement System using a Thermistor

\section{Conveyor Control System using State Machine}

The purpose of this lab project is to use LabVIEW with the myDAQ to design a conveyor control system utilizing the pre-built conveyor simulator and infrared proximity sensors ${ }^{5}$. The engineering requirements are listed below. The pre-built conveyor simulator is shown in Figure 2.

Special features:

- Program designed using LabVIEW

- Software development using a state machine

- Pre-built conveyor simulator will be used for your system

- Conveyor simulator will be interfaced to the myDAQ device User Interface Requirements:

- A Boolean control on the front panel to indicate that the conveyor is ready to be started

- A display on the front panel to indicate the state of the conveyor

- A button (or toggle switch) on the front panel to simulate the stamping action

- An emergency stop button to terminate the program

Functional Requirements: 
- If no part is on the conveyor it will not operate

- When a part is placed in front of the first sensor and the ready button is pressed, the part automatically moves to the second sensor

- When the part reaches the second sensor, the conveyor stops to allow the part to be stamped

- The part stamp can't function unless the conveyor has stopped and the part is in front of the second sensor

- After the part is stamped, it will automatically continue to the end

- After the part reaches the end, the conveyor stops and the system waits for a new part to be placed in front of the first sensor

- The emergency stop button is monitored every $100 \mathrm{mS}$

Operating Sequence:

- Once program is started it waits for user to be ready

- Once the ready button is pressed, the program checks for a part on the conveyor in front of the first sensor

- If no part is found in front of the first sensor, the program displays the error and re-loops back to wait for the user

- If a part is found, the conveyor starts and the part begins moving down the conveyor

- The program displays to the user that the conveyor is moving

- When the part reaches the second sensor, the conveyor stops, the part gets stamped, and the part continues to the end of the conveyor

- The conveyor stops when the part reaches the end of the conveyor.

- The program waits until the part is removed from the conveyor, and then the program reloops (assuming the emergency stop button is not depressed).

- If the emergency stop button is depressed, the conveyor stops immediately (within 200mS), program notifies user, and program stops.
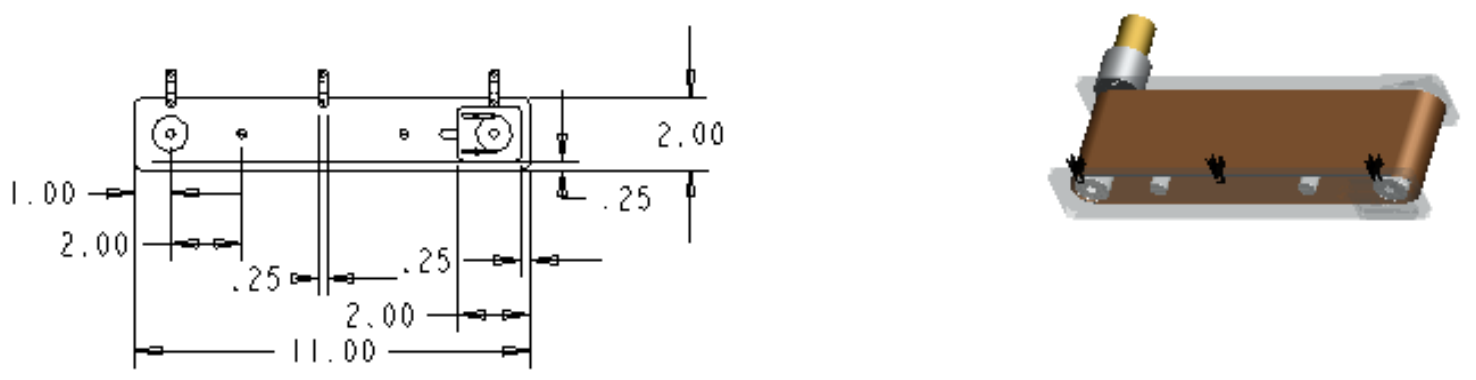

Figure 2. Pre-built conveyor simulator

Prior to this lab, students were introduced to state machines during a lecture class in which they designed a traffic light controller. At the beginning of this lab, students were provided a PowerPoint file that contained information to assist them in starting their design of the state machine, reading the status of the three proximity sensors, and designing the sensor (LED and Phototransistor) driver circuits ${ }^{6}$. A screen capture of the block diagram of one state of the instructor's state machine is shown in Figure 3. In this figure, the sensor inputs are simulated as digital inputs. Figure 4 shows a screen capture of a LabVIEW program illustrating how to read from the three input sensors and how to write an output for controlling the DC motor on the conveyor. Figure 5 provides an example of a driver circuit for the DC motor. An example of the screen capture of a student's LabVIEW front panel, LabVIEW block diagram, and schematic are shown below in Figure 6. 


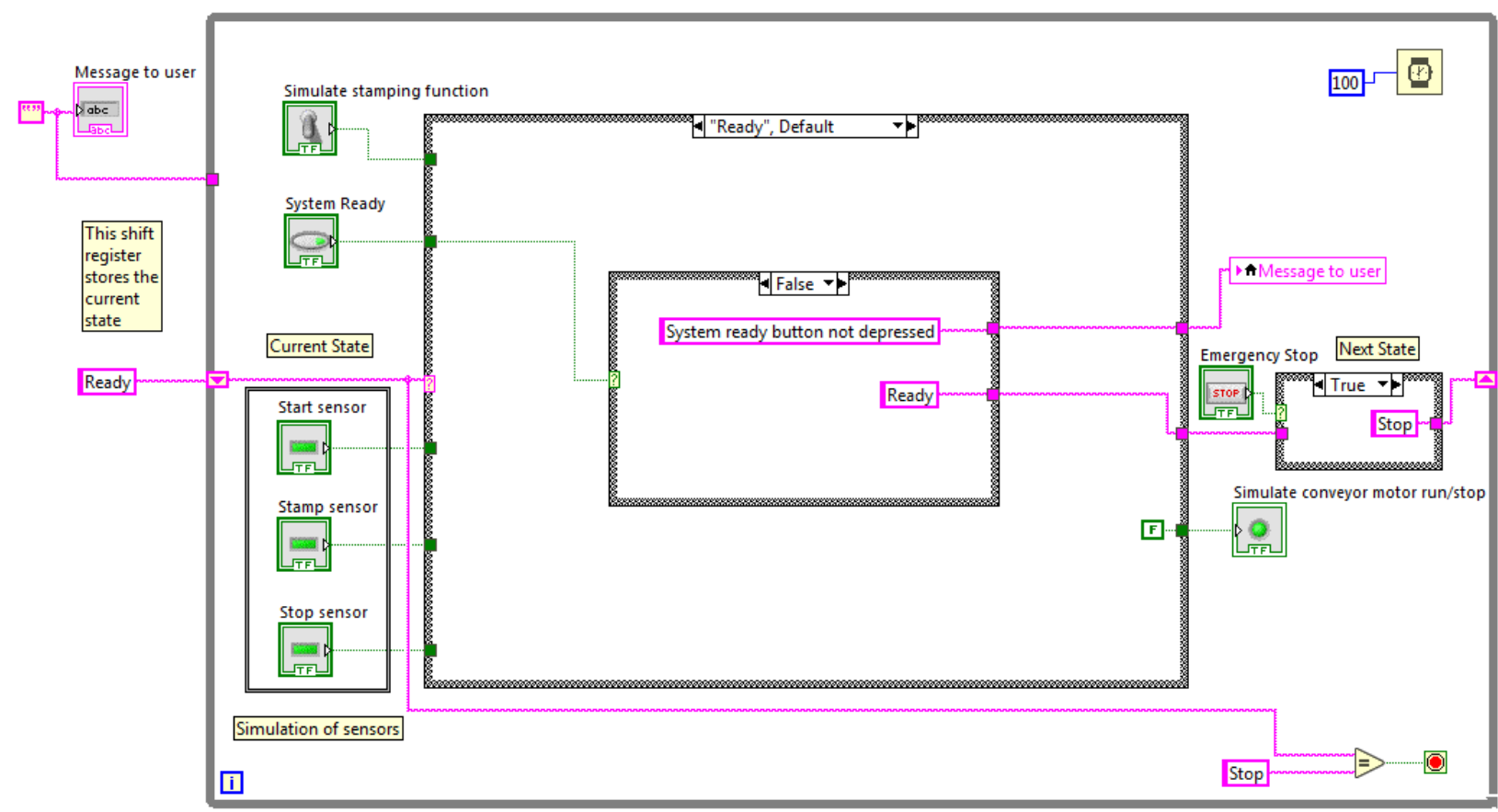

Figure 3. LabVIEW block diagram example of state machine for Conveyor Control System

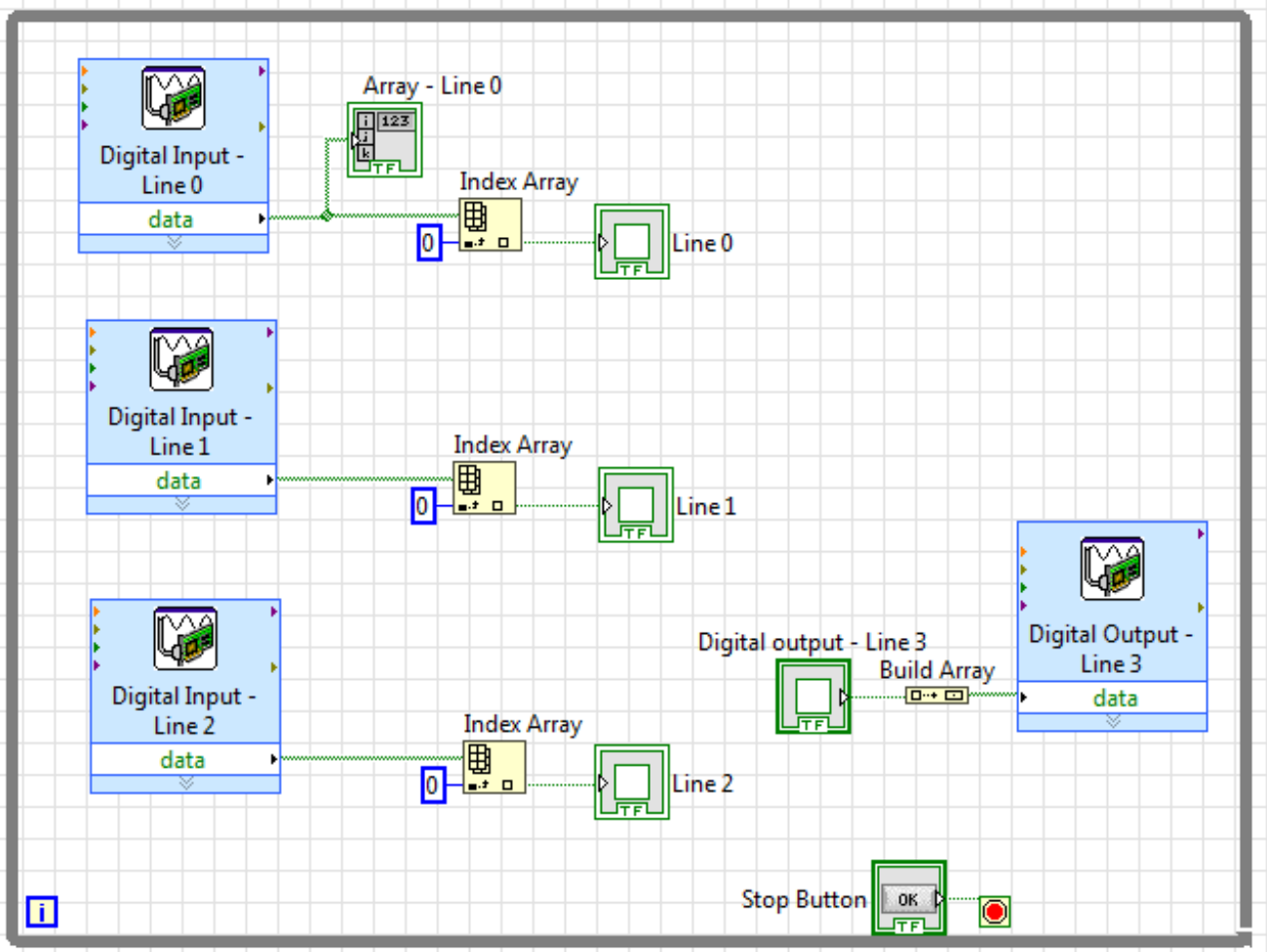

Figure 4. LabVIEW block diagram of Digital I/O 
SN754410

DC motor voltage (pin 8)

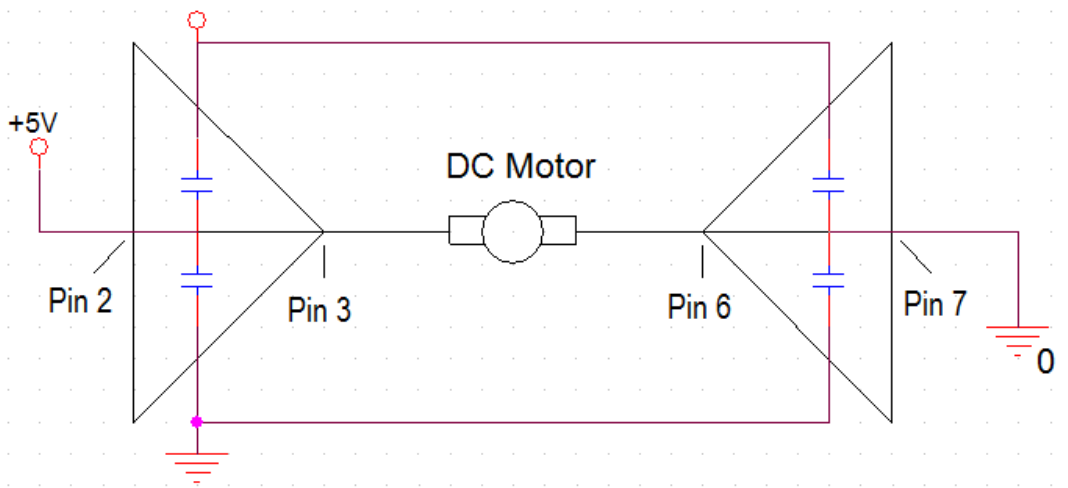

Ground (pins 4,5)

Also:

- connect $+5 \mathrm{~V}$ to pin 16

Figure 5. Driver circuit for DC motor on pre-built conveyor simulator

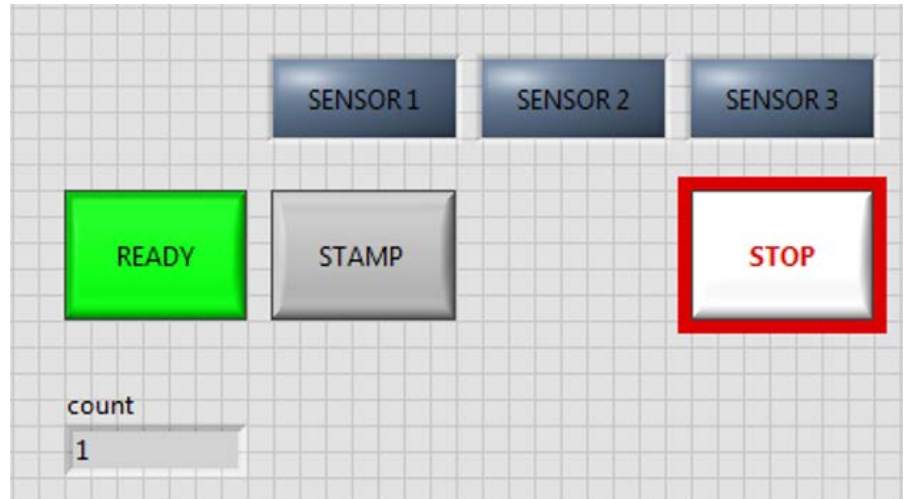

Figure 6(a). LabVIEW front panel of Conveyor Control System 


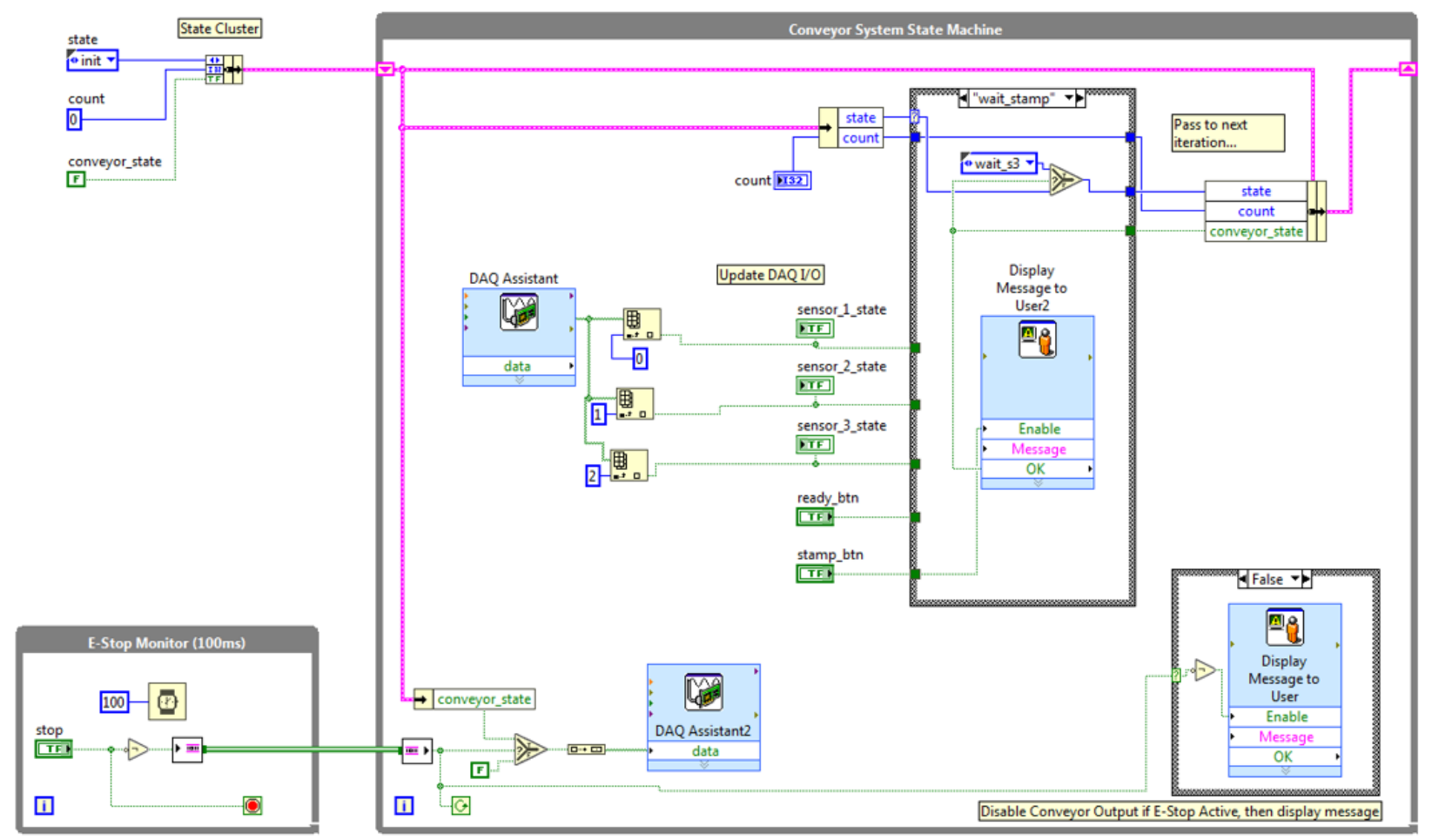

Figure 6(b). LabVIEW block diagram of Conveyor Control System

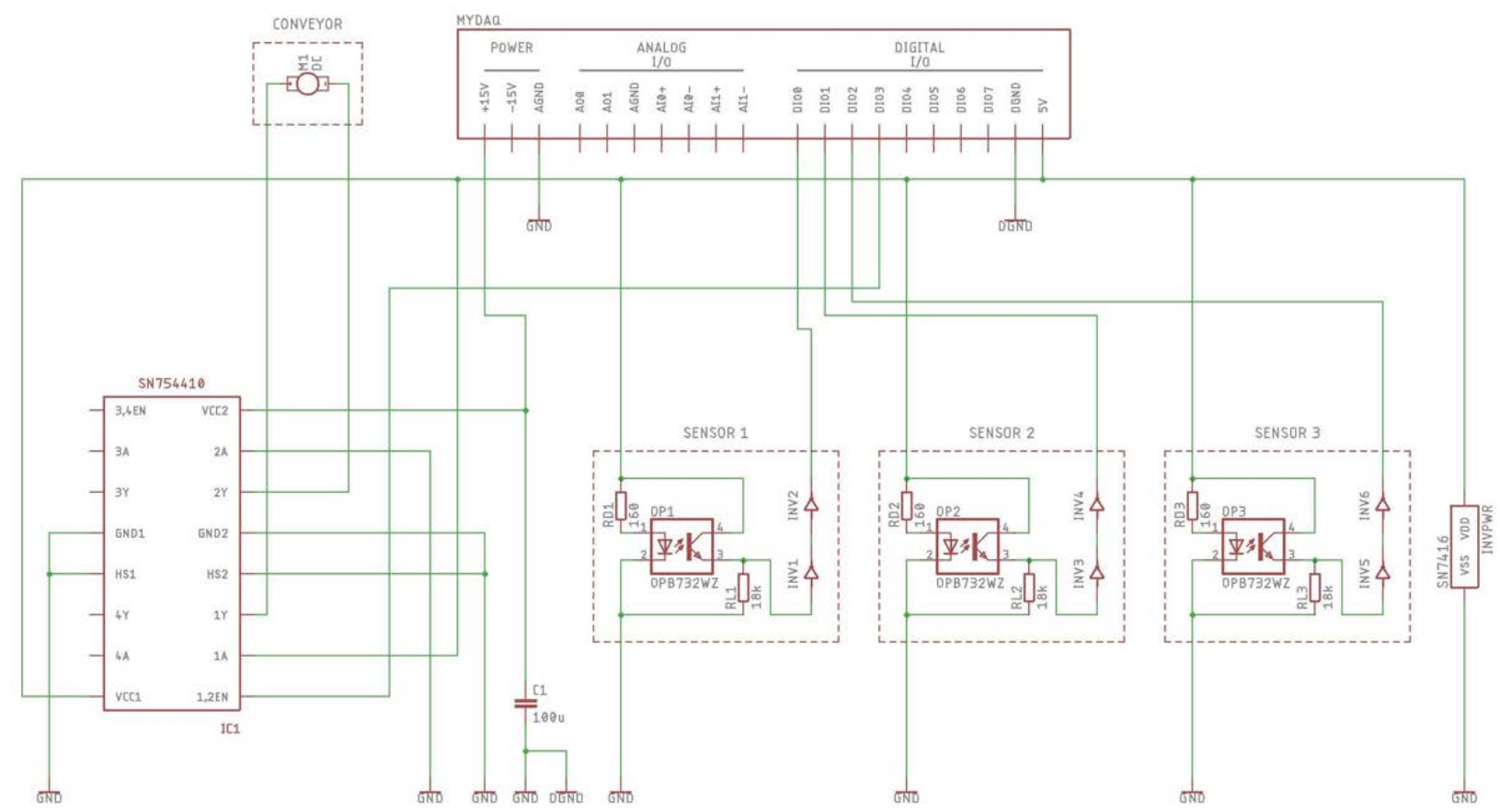

Figure 6(c). Schematic of Conveyor Control System

\section{Measurement System for Applied Mass}

The purpose of this lab experiment is to design a measurement system to measure the mass applied to a rectangular beam, which has an attached strain gage. 
Special features:

- Program designed using LabVIEW

- Mass applied to an aluminum beam with 3-wire strain gage mounted on beam

- Bridge circuit with an instrumentation amplifier (AD620) used for signal conditioning User Interface Requirements:

- One numeric indicator showing the applied mass in Kg Functional Requirements:

- Measurement range: 0 to $5 \mathrm{Kg}$

- Accuracy of measurement: within $+/-0.5 \mathrm{Kg}$

The beam and strain gage are shown in Figure 7. The gage factor of the strain gage was provided to the students, and the students measured the dimensions of the beam. After designing their signal conditioning circuit, it was calibrated at no load and at full-scale. An example of the screen capture of a student's LabVIEW front panel, LabVIEW block diagram, and schematic are shown below in Figure 8.

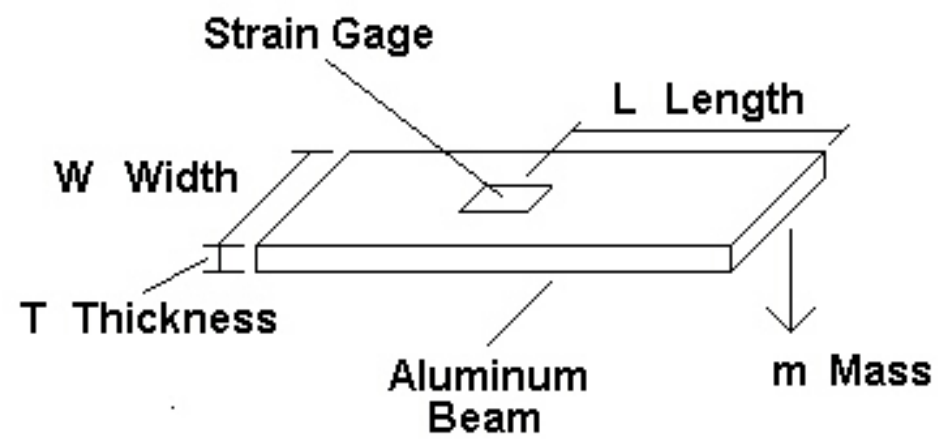

Figure 7. Strain gage attached to aluminum beam

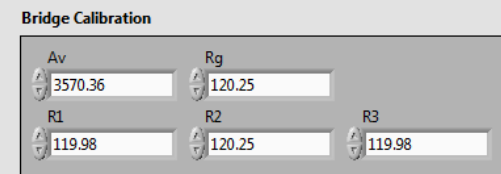

Beam/Sensor Calibration

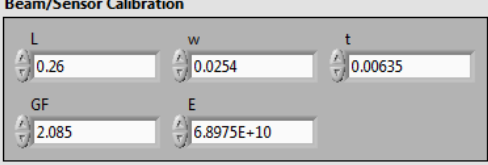

Weight
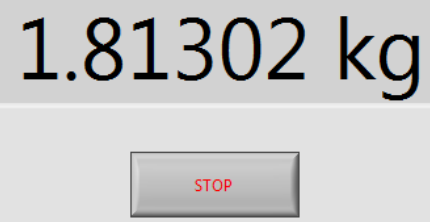

$0.00102:$ Vbridge

Figure 8(a). LabVIEW front panel of measurement system for applied mass 


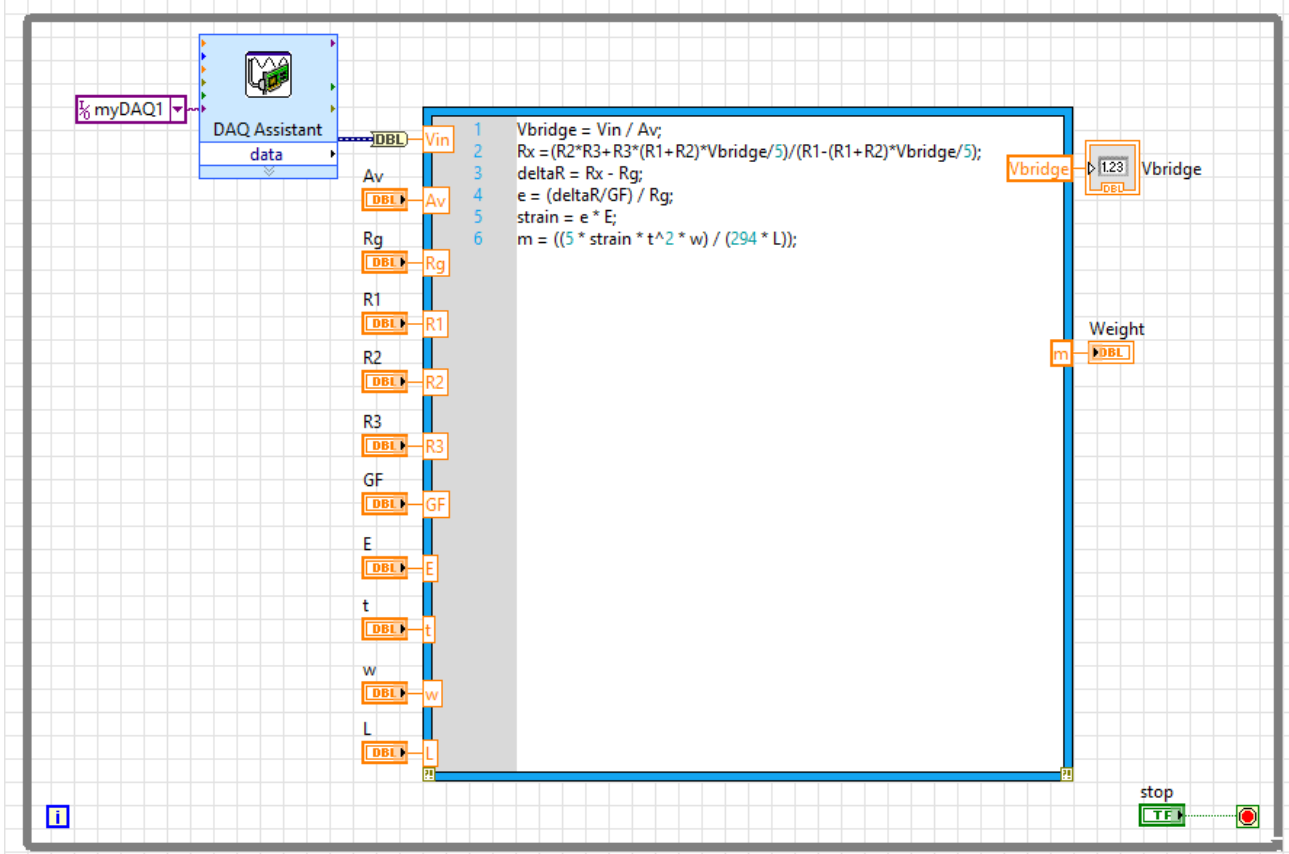

Figure 8(b). LabVIEW block diagram of measurement system for applied mass

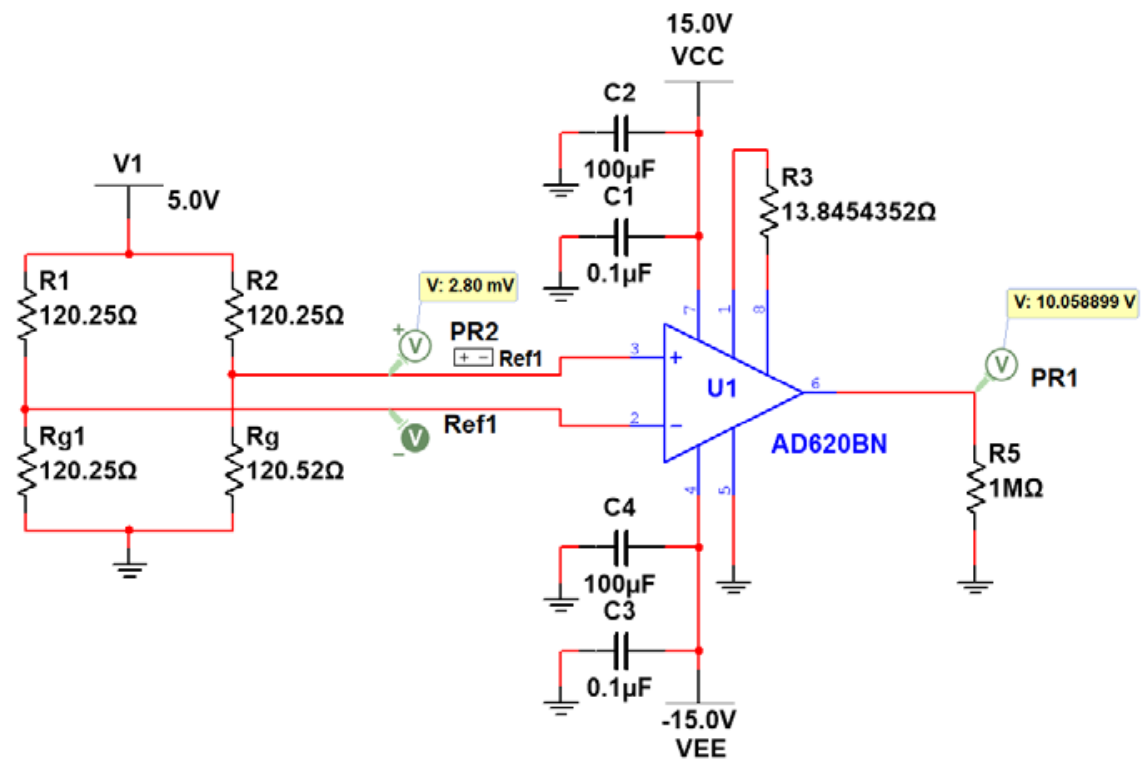

Figure 8(c). Schematic of measurement system for applied mass

\section{Machine Vision}

The purpose of this lab project is to use LabVIEW with a USB webcam to detect the positions and number of electronic devices (DIPs of varying sizes and a transistor) on a breadboard. Requirements for the lab include software identification of four DIPs of varying sizes and one transistor, by placing a bounding box around each object, specifying the $\mathrm{X}$ and $\mathrm{Y}$ center coordinates of each object, specifying the $\mathrm{X}$ and $\mathrm{Y}$ coordinates of each bounding box, and specifying the area of each object. 
For this lab project, students were provided information to assist them in using the LabVIEW Vision Assistant to acquire and save images of objects using a USB webcam, using the LabVIEW Vision Acquisition Express VI and the IMAQ Write File 2 VI to programmatically acquire and save images of objects using the same USB webcam, and using additional subVIs for object detection. Figure 9 provides screen captures of the instructor's LabVIEW front panel and block diagrams.

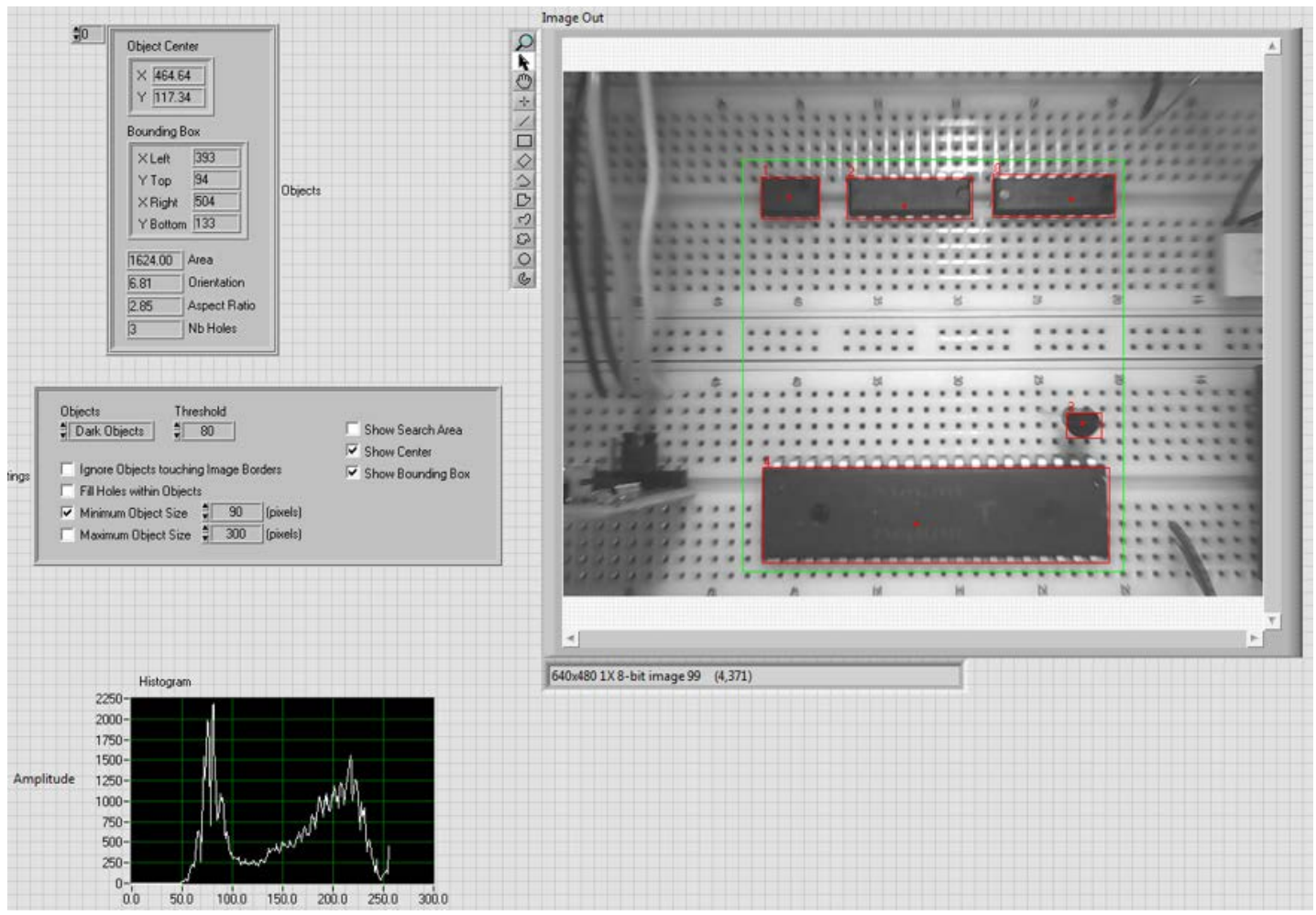

Figure 9(a). LabVIEW front panel of vision system

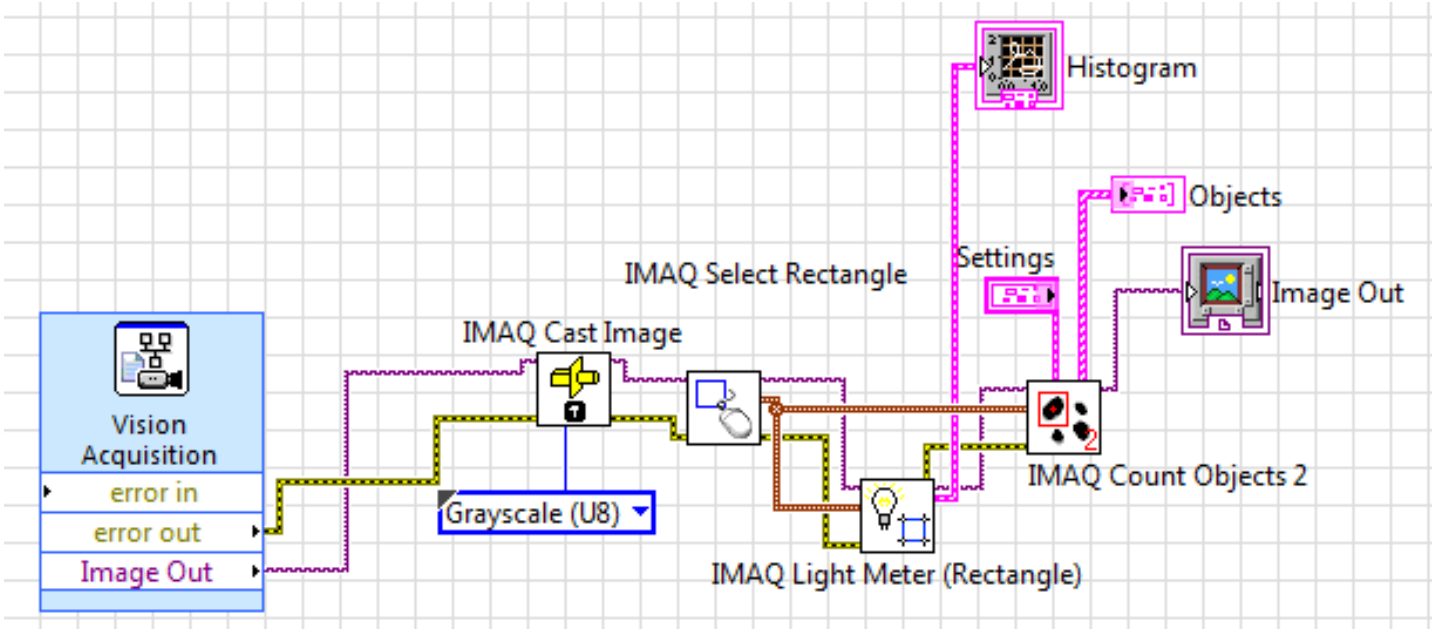

Figure 9(b). LabVIEW block diagram of vision system 


\section{LabVIEW Instrument Control}

The purpose of this lab is to use LabVIEW to design an instrument control system for the 3012A Agilent Digital Storage Oscilloscope (DSO) to automatically determine the frequency response characteristics of a passive $1^{\text {st }}$ order lowpass filter with a cutoff frequency of $1 \mathrm{KHz}$. A PC is connected to the DSO using the USB port. Requirements for the lab project include providing inputs for start and stop frequencies, and for frequency spacing, and providing outputs showing measured values for filter output frequencies and amplitudes.

For this lab project, a PowerPoint file is provided to students. This file shows information regarding the LabVIEW Virtual Instrument Software Architecture (VISA) subVIs, the Standard Commands for Programmable Instruments (SCPI) (e.g., common, query, and device-specific), and SCPI status reporting ${ }^{4}$. An example showing the device-specific commands for configuring the waveform generator (internal to the DSO) is provided to the students in this PowerPoint file, and it is shown below in Figure 10. A state machine architecture is needed to meet the requirements for this lab project. Figure 11 provides screen captures of the instructor's LabVIEW front panel and block diagrams for the instrument control system. In Figure 11(b), the DSO commands for reading frequency and amplitude values are shown.

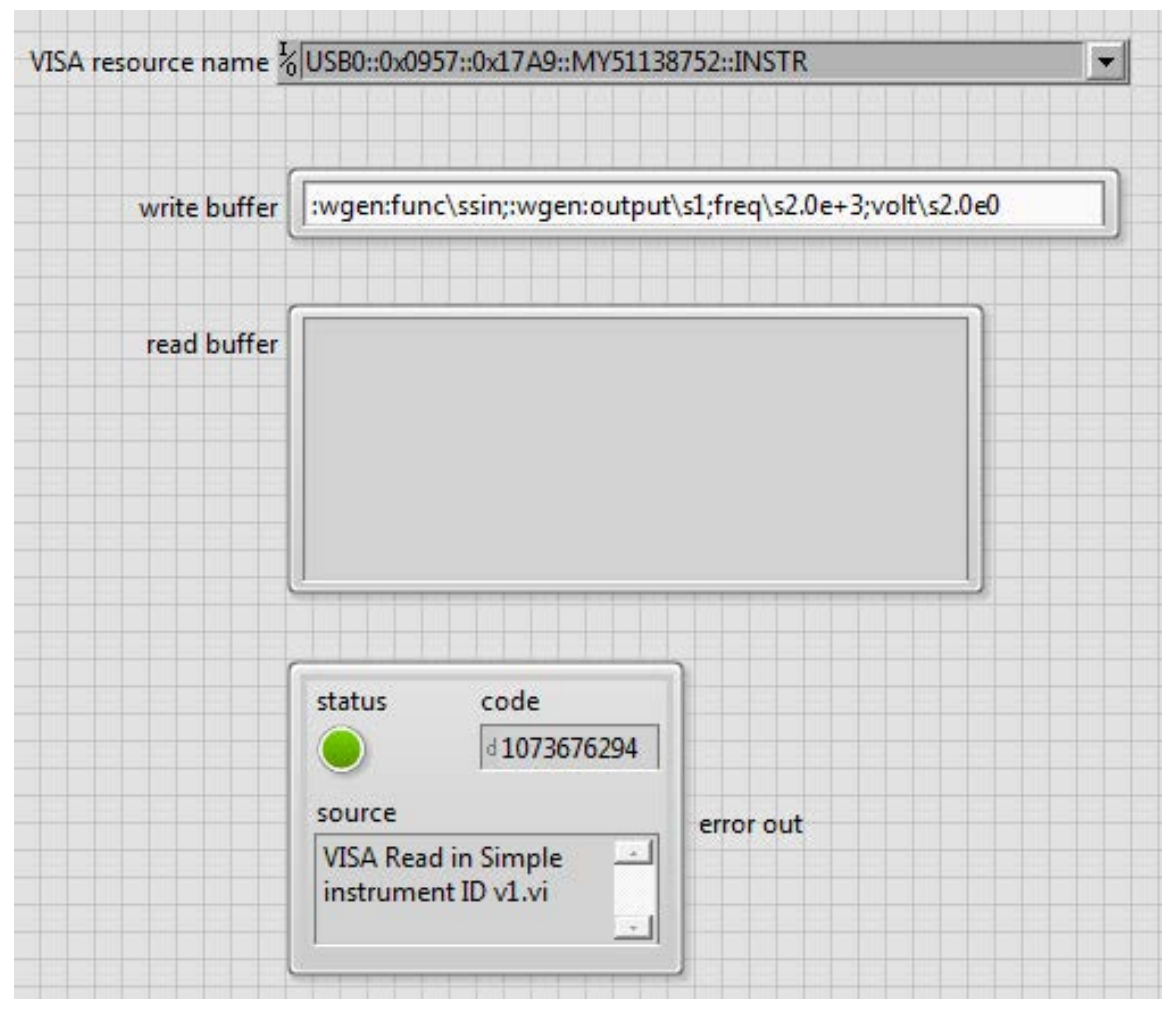

Figure 10. Commands for configuring the waveform generator 


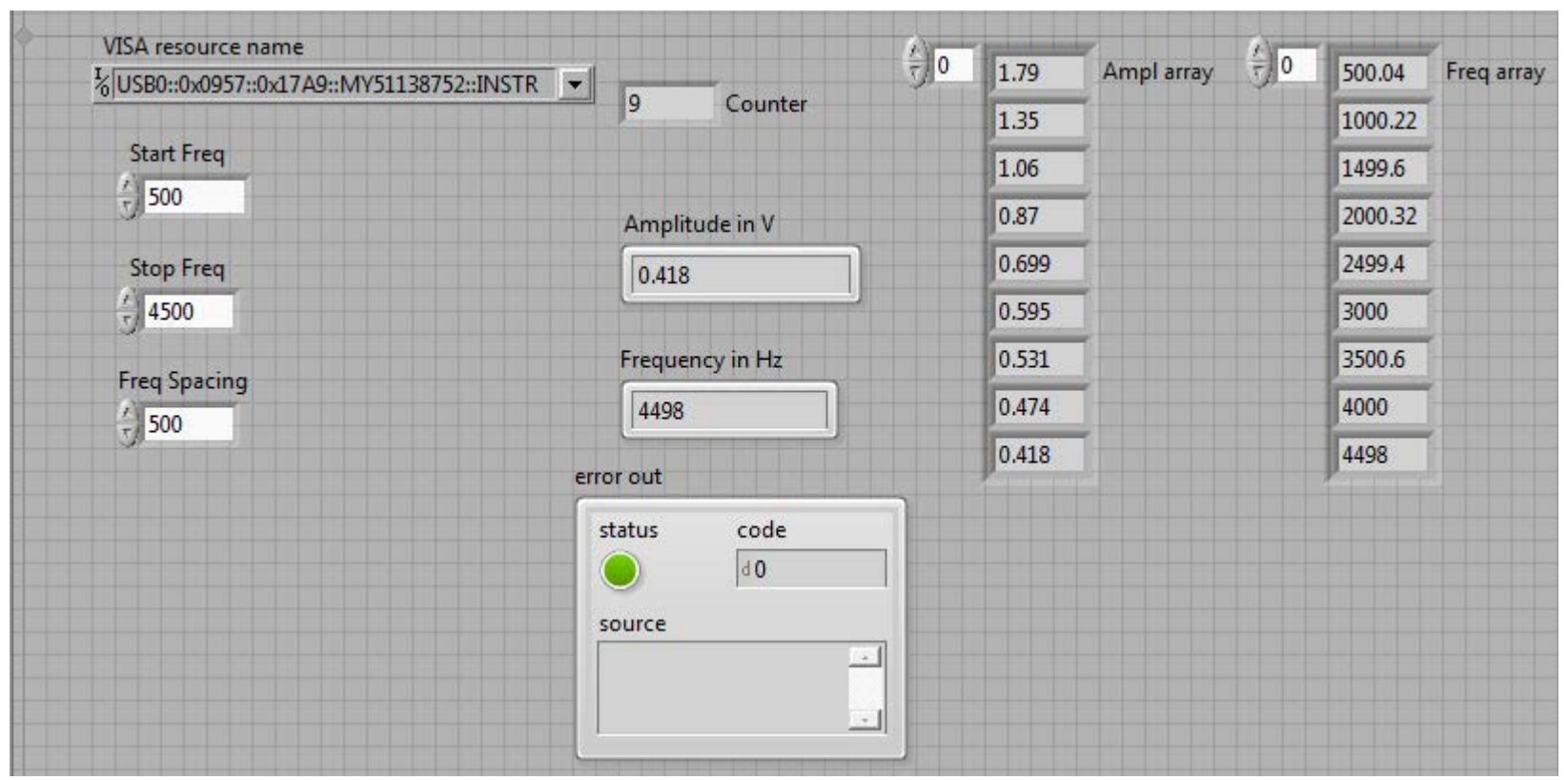

Figure 11(a). LabVIEW front panel of instrument control system

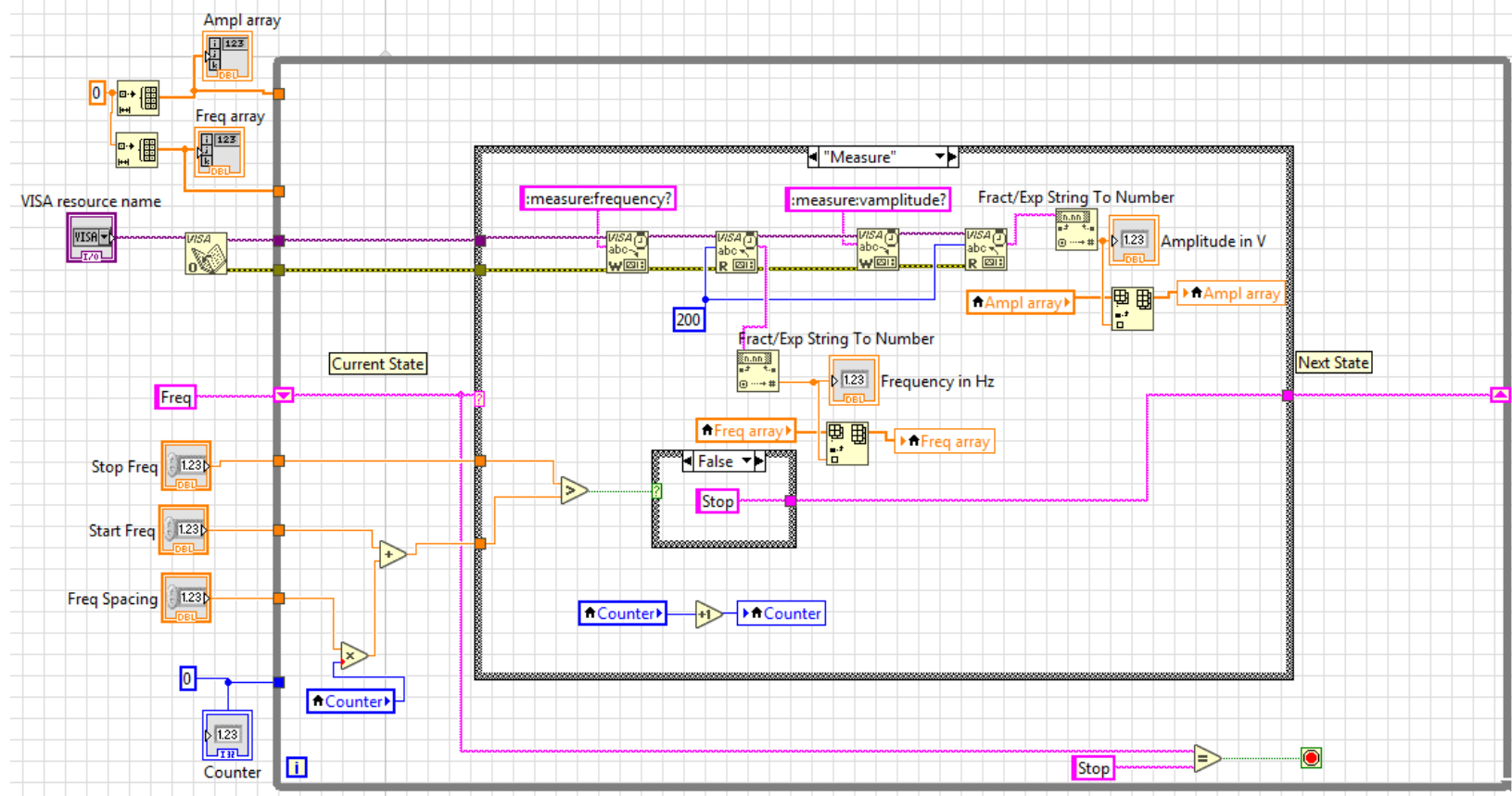

Figure 11(b). LabVIEW block diagram of instrument control system

\section{Instructor Assessment}

The first ten labs were successfully completed by the students. For Lab 9 (Signal Conditioning Circuit for an RTD) and Lab 10 (Measurement System for Applied Mass), students needed additional time calibrating the circuits. Thus, the instructor allowed the students to utilize one more week for each lab completion. This resulted in insufficient time for students to complete Lab 12 (Instrument Control) and only three teams able to complete Lab 11 (Machine Vision) as extra credit. 
For labs that required only one week to complete, each lab grade was worth 50 points, and the remaining labs were worth 100 points each. The one exception was Lab 11, since it was extra credit and only worth 30 points. Requirements for lab reports were included with each lab handout. Each lab consisted of a series of steps, with outcomes and available points indicated for each step. Depending upon the lab, outcomes included screen captures of LabVIEW front panels and block diagrams, screen captures of circuit schematics and simulation results, tables of results, equations, text summaries, team demonstrations, etc. For each lab report, grades averaged from 85\% to 98\%, and only one lab report is required for each team. Overall, the lab report grades were high since nearly every student team completed the requirements for every lab.

\section{Student Assessment}

Students were asked to complete an assessment of the labs. Out of 16 students in the course for fall 2018, six students completed the assessment. Assessment results are summarized in Table 1.

\begin{tabular}{|c|c|}
\hline Questions & Responses \\
\hline $\begin{array}{l}\text { Approximate average number of } \\
\text { hours you worked on lab projects } \\
\text { per week }\end{array}$ & $\begin{array}{l}\text { Specific student comments from none (for the first several } \\
\text { labs) to } 2 \rightarrow 10,5 \rightarrow 8,4 \rightarrow 5,5 \rightarrow 10,3 \rightarrow 8 \text {, and } 5 \text {. Students } \\
\text { indicated that it varied, depending upon the lab. }\end{array}$ \\
\hline $\begin{array}{l}\text { Approximate average level of } \\
\text { difficulty for lab projects based } \\
\text { on junior year standing } \\
(1 \rightarrow 5 \text {, with } 1 \text { as extremely easy, } \\
3 \text { as moderately difficult, } 5 \text { as } \\
\text { extremely difficult) }\end{array}$ & $\begin{array}{l}\text { Specific student comments ranged mainly from } 3 \text { to } 5 \text {. One } \\
\text { student commented that the first several labs were from } 1 \text { to } 3 \text {. }\end{array}$ \\
\hline $\begin{array}{l}\text { Which lab project was the most } \\
\text { difficult? Briefly explain why. }\end{array}$ & $\begin{array}{l}\text { - Title: Labs } 9 \text { \& } 10 \text { were specified by students. } \\
\text { - Why? Students commented about breadboarding and } \\
\text { calibrating problems. }\end{array}$ \\
\hline $\begin{array}{l}\text { Which lab project was the least } \\
\text { difficult? Briefly explain why. }\end{array}$ & $\begin{array}{l}\text { - Title: Labs } 1 \text { \& } 11 \text { were specified by students. } \\
\text { - Why? Lab } 1 \text { since it was an introduction to LabVIEW and } \\
\text { Lab } 11 \text { since the design followed from the examples } \\
\text { provided by the instructor }\end{array}$ \\
\hline $\begin{array}{l}\text { List areas of difficulty to } \\
\text { successfully complete lab } \\
\text { projects }\end{array}$ & $\begin{array}{l}\text { Student comments regarding circuit breadboarding, calibration, } \\
\text { time management, and working together as a team. }\end{array}$ \\
\hline Suggestions for Improvement & $\begin{array}{l}\text { Student comments regarding additional vision labs, provide } \\
\text { helpful hints on labs, fewer labs, and making labs simpler. }\end{array}$ \\
\hline Other Comments & $\begin{array}{l}\text { Student comments included great overall class and fun } \\
\text { semester. }\end{array}$ \\
\hline
\end{tabular}

Table 1. Student Assessment Results

\section{Conclusions /Recommendations}

LabVIEW with the myDAQ provided an excellent development environment for this course to design both measurement and control systems. The University anticipates students to place six to nine hours of productive outside class time per week for a three-credit course. Thus, the time effort 
specified by students in the assessment is reasonable, considering that other time is needed for homework, studying for exams, etc. The level of difficulty specified by students ranged from extremely easy (for the first several labs) to extremely difficult. This is expected, since the first several labs introduce LabVIEW with basic applications, while the scope of most of the remaining labs include the design of measurement and/or control systems.

It is anticipated that Lab 9 will be re-designed to reduce the breadboarding and calibration required to complete the lab. This may be accomplished by utilizing the signal conditioning available from within the myDAQ. Additionally, the signal conditioning circuit (bridge circuit and instrumentation amplifier) required for Lab 10 may be able to be simplified to minimize the time required for calibration. These changes may also enable sufficient time for students to complete Lab 12.

\section{Acknowledgement}

We would like to thank the students in the Measurements \& Instrumentation course who completed the labs and the lab assessment. Specifically, we would like to thank Seth Duke and Zachary Mansfield who provided screen captures for the student figures.

\section{Bibliography}

1. Loker, D. and Strom, S. “Automated Test \& Measurement System for a Power Supply and Control Board,” Annual Meeting, American Society for Engineering Education, 2016, 16 pp.

2. Bishop, Robert H., Learning with LabVIEW 2009, Pearson Education, 2010.

3. Travis, Jeffrey and Jim Kring, LabVIEW for Everyone, $3^{\text {rd }}$ Edition, Pearson Education, 2007.

4. Essick, John, Hands-On Introduction to LabVIEW for Scientists and Engineers, $2^{\text {nd }}$ Edition, Oxford University Press, 2013.

5. Loker, D., Weissbach, R., and Henry, A., “Conveyor Control System Project,” Annual Meeting, American Society for Engineering Education Annual Conference, 2011, 14 pp.

6. Web site https://www.mouser.it/datasheet/2/414/OPB732_1-1141082.pdf 